\title{
MUDAS DE MAMÃO CV. SUNRISE SOLO BS 2000 PRODUZIDAS COM LODO DE CURTUME EM MISTURA COM SUBSTRATO COMERCIAL
}

\author{
PAPAYA SEEDLINGS CV. SUNRISE SOLO BS 2000 PRODUCED WITH \\ TANNERY SLUDGE IN MIXTURE WITH COMMERCIAL SUBSTRATE
}

\author{
${ }^{1}$ Otto Herbert Schuhmacher Dietrich \\ ${ }^{2}$ Márcia Adriana Carvalho dos Santos \\ ${ }^{3 *}$ Vinicius Rodrigues Ferreira \\ ${ }^{4}$ Sávio da Silva Berilli \\ ${ }^{5}$ Euliene Pereira Henrique \\ ${ }^{6}$ Laís Barboza Rozaes \\ ${ }^{7}$ Ana Paula Cândido Gabriel Berilli
}

\begin{abstract}
${ }^{1}$ Instituto Federal de Educação, Ciência e Tecnologia do Espirito Santo - IFES, Campus Barra de São Francisco-
ES. E-mail: otto.dietrich@ifes.edu.br

${ }^{2}$ Embrapa Semiárido, Petrolina-PE. E-mail: marciagro3@yahoo.com.br

${ }^{3}$ Instituto Federal de Educação, Ciência e Tecnologia do Espirito Santo - IFES, Campus de Alegre -ES, Brasil.

E-mail: rodrigues.ufes@gmail.com

${ }^{4}$ Instituto Federal de Educação, Ciência e Tecnologia do Espirito Santo - IFES, Campus de Alegre-ES. E-mail: berilli@gmail.com

${ }^{5}$ Instituto Federal de Educação, Ciência e Tecnologia do Espirito Santo - IFES, Campus de Alegre-ES. E-mail: euliene.pereira@gmail.com

${ }^{6}$ Instituto Federal de Educação, Ciência e Tecnologia do Espirito Santo - IFES, Campus de Alegre-ES. E-mail: laisbarbozarozaes@gmail.com

${ }^{7}$ Instituto Federal de Educação, Ciência e Tecnologia do Espirito Santo - IFES, Campus de Alegre-ES. E-mail: anapaulacg@gmail.com *Autor de correspondência
\end{abstract}

Artigo submetido em 13/04/2021, aceito em 06/06/2021 e publicado em 02/07/2021.

Resumo: O aproveitamento de resíduos para fabricação de substratos pode ser uma estratégia de baixo custo aos produtores de mamão. Assim, objetivou-se avaliar o efeito do lodo de curtume como substrato para produção de mudas de mamão cv. Sunrise Solo BS 2000. As proporções 0, 15, 30, 45 e $60 \%$ de lodo de curtume foram experimentadas em mistura com substrato comercial Carolina II®, usado por viveristas de mamão. Um delineamento em blocos casualizados foi utilizado para produzir as 150 mudas de mamão. As características de emergência foram avaliadas durante os sete primeiros dias. As biométricas, gravimétricas e de qualidade de mudas aos trinta e cinco dias. Os resultados foram submetidos ao teste $\mathrm{F}$ e de Dunnett $(\mathrm{p}<0,05)$. A emergência das mudas de mamão e o número de folhas foram similares entre o substrato comercial e as proporções até $30 \%$ de lodo de curtume, executando-se a proporção de $15 \%$ para IVE. Apenas a proporção de $15 \%$ de lodo não afetou os parâmetros de diâmetro do caule, área foliar e de qualidade das mudas em relação ao uso somente do substrato comercial. As variáveis de emergência, número de folhas, altura da planta, diâmetro do colo, área foliar, gravimétricas e de qualidade apresentaram valores médios menores a medida dos aumentos 
graduais do lodo de curtume, à exceção do tempo médio de emergência. Portanto, a mistura de lodo de curtume ao substrato comercial limitou o desenvolvimento e a qualidade das mudas de mamoeiro cv. Sunrise Solo BS 2000.

Palavras-chave: propagação; resíduo alternativo; redução de custos; sustentabilidade; Carica papaya.

\begin{abstract}
The use of waste for substrate manufacturing can be a low-cost strategy for papaya producers. Thus, the objective of this study was to evaluate the effect of tannery slat as substrate for production of cv papaya seedlings. Sunrise Solo BS 2000. The proportions 0, 15, 30, 45 and 60\% of tannery sludge were tried in mixture with commercial substrate Carolina II ${ }^{\circledR}$, used by papaya viverists. A randomized block design was used to produce the 150 papaya seedlings. Emergency characteristics were evaluated during the first seven days. Biometrics, gravimetric and seedling quality at thirty-five days. The results were submitted to the $F$ and Dunnett test $(p<0.05)$. The emergence of papaya seedlings and the number of leaves were similar between the commercial substrate and the proportions up to $30 \%$ of tannery sludge, performing the proportion of $15 \%$ for IVE. Only the proportion of $15 \%$ of stem did not affect the parameters of stem diameter, leaf area and seedling quality in relation to the use of only commercial substrate. The variables of emergence, number of leaves, plant height, neck diameter, leaf area, gravimetric and quality presented lower mean values to measure the gradual increases of tannery sludge, except for the mean time of emergence. Therefore, the mixture of tannery sludge to the commercial substrate limited the development and quality of the seedlings of papaya tree cv. Sunrise Solo BS 2000.
\end{abstract}

Keywords: propagation; alternative waste; cost reduction; sustainability; Carica papaya.

\section{INTRODUÇÃO}

No ano de 2019, o Brasil obteve uma produção de 1.161.808 de toneladas de mamão (FAO, 2021). Cerca de 64,3\% dessa produção é oriunda dos estados da Bahia e Espírito Santo (EMBRAPA, 2018). O cultivo dessa frutícola representa grande geração de empregos e renda no campo, inclusive pela necessidade de renovação dos plantios, que é em média a cada três anos (NOMURA et al., 2019). No estabelecimento de pomares de mamoeiro, a etapa de propagação pode influenciar diretamente na produtividade (COSTA JÚNIOR et al., 2017). Um bom padrão de muda significa uniformidade no estande e rápida formação de plantas (SILVA-MATOS et al., 2016).

Dentre os fatores que contribuem para o sucesso dessa fase inicial, destaca-se o uso de um substrato com boa composição (CALDEIRA et al., 2012). No entanto, apesar da qualidade dos substratos comerciais, estes podem ser inviáveis aos pequenos produtores de mamão, em vista do seu alto valor de aquisição (MORAIS et al., 2017). Por essa razão, a produção de substratos alternativos tem ganhado visibilidade, principalmente aqueles fabricados a partir de resíduos como o lodo de curtume (BERILLI et al., 2019; ALMEIDA et al., 2017; SALES et al., 2018).

O lodo de curtume promoveu bons resultados quando adicionado em um substrato comercial, para produção de mudas de pimenta biquinho (ALMEIDA et al., 2017). Esse resíduo ainda foi testado na produção de mudas de diversas outras culturas como café (QUATERZANI et al., 2018), palmeira-garrafa (BERILLI et al., 2018), maracujá (SALES et al., 2018) e pimenta doce (BERILLI et al., 2019), obtendo-se bons resultados. Porém, pesquisas com aplicação do lodo de curtume na produção de mamoeiros são carentes, mesmo havendo disponibilidade desse resíduo na região noroeste do estado do Espírito Santo, próxima as vastas lavouras de mamoeiros do norte do estado (BARROS et al., 2014).

Sob outra perspectiva, as indústrias curtumeiras necessitam de soluções 
adequadas para descarte de seus resíduos, visto que podem possuir elementos nocivos ao meio ambiente como sulfetos, cromo e sódio (QUADRO et al., 2018; COMÉRIO et al., 2019). As elevadas concentrações de cromo podem ocasionar diversos distúrbios que afetam os processos metabólicos, vitais as plantas (PLUGARU et al., 2016; SOUZA; SANTOS, 2018). Uma salinidade excessiva pode reduzir o potencial osmótico do substrato, prejudicando a absorção de água pelas raízes (ALMEIDA et al., 2018).

O aproveitamento do lodo de curtume na produção agrícola requer conhecimentos sobre seus possíveis danos as plantas (POSSATO et al., 2014). Isto posto, além do propósito de aproveitar ao máximo os recursos disponíveis próximos aos viveiros de mudas de mamoeiros, objetivou-se avaliar a influência do lodo de curtume em mistura com substrato comercial Carolina II®, na produção de mudas de mamão cultivar Sunrise Solo BS 2000. Essa cultivar é popularmente utilizada por produtores de mamão, devido a preferência de mercado e possuírem genótipos geneticamente uniformes (DANTAS et al., 2015).

\section{MATERIAIS E MÉTODOS}

O experimento foi desenvolvido em condições de casa de vegetação, no município de Sooretama/ES, sob as coordenadas geográficas $19^{\circ} 10^{\prime} 13,7^{\prime \prime}$ de latitude sul, e $40^{\circ} 05^{\prime} 17,3^{\prime \prime}$ de longitude oeste, com altitude de 62,8 metros. A casa de vegetação é coberta com plástico transparente e sombrite de 50\%, com irrigação automatizada. O experimento foi conduzido em delineamento em blocos casualizados com cinco blocos. Os tratamentos constituíram de cinco diferentes proporções de lodo de curtume e substrato comercial Carolina II ${ }^{\circledR}$, sendo este tipicamente usado na propagação de plantas de mamoeiro (Tabela 1). A parcela experimental foi constituída de 6 mudas, totalizando 150 mudas no experimento.

Tabela 1: Descrição dos tratamentos contendo lodo de curtume e substrato comercial Carolina II ${ }^{\circledR}$, nas suas diferentes proporções.

\begin{tabular}{rc}
\hline Tratamentos & $\begin{array}{c}\text { Componente do } \\
\text { Substrato* }\end{array}$ \\
\hline $\mathrm{T}-00$ & $100 \%$ de Carolina II ${ }^{\circledR}$ \\
$\mathrm{T}-15$ & $15 \%$ de lodo de \\
& curtume $+85 \%$ de Carolina \\
& II ${ }^{\circledR}$ \\
$\mathrm{T}-30$ & $30 \%$ de lodo de \\
& curtume $+70 \%$ de Carolina \\
& II ${ }^{\circledR}$ \\
$\mathrm{T}-45$ & $45 \%$ de lodo de \\
& curtume $+55 \%$ de Carolina \\
& II ${ }^{\circledR}$ \\
$\mathrm{T}-60$ & $60 \%$ de lodo de \\
& curtume $+40 \%$ de Carolina \\
& II ${ }^{\circledR}$
\end{tabular}

O lodo de curtume foi cedido pela empresa Capixaba Couros LTDA, localizada no município de Baixo Guandu/ES, região noroeste do estado. O lodo é um resíduo proveniente do curtimento do couro bovino, sendo coletado dos tanques de decantação do processo de tratamento de água residuária dos curtumes. O material orgânico presente foi pré-decomposto por processo anaeróbico e após retirada do lodo (material sedimentado) passou por desidratação ao ar livre (exposição ao sol) (Tabela 2).

Não foi realizado análise química do substrato comercial, pois na embalagem já continha as especificações. Este substrato, de acordo com especificações da empresa produtora, apresenta: turfa de esfagno, vermiculita expandida, resíduo orgânico de agroindústria classe A (casca de arroz torrefada), calcário dolomítico, gesso agrícola e fertilizante NPK. (traços). Potencial hidrogeniônico (pH): 5,5 +/- 0,5; condutividade elétrica (CE): $0,7+/-0,3$; densidade: $145 \mathrm{~kg} / \mathrm{m}^{3}$; capacidade de 
retenção de água (CRA): 55\%; umidade máxima: 50\%.

Tabela 2. Características químicas do lodo de curtume

\begin{tabular}{ccc}
\hline Parâmetro & Unidade & Resultado \\
\hline \multicolumn{2}{c}{$\mathrm{pH} \mathrm{em} \mathrm{CaCl}_{2}$} & 7,28 \\
$\mathrm{C} / \mathrm{N}$ & & $9 / 1$ \\
$\mathrm{MOT}$ & $\mathrm{g} \mathrm{dm}^{-3}$ & 300,57 \\
$\mathrm{C}$ org. & $\mathrm{g} \mathrm{dm}^{-3}$ & 160,98 \\
$\mathrm{MOC}$ & $\mathrm{g} \mathrm{dm}^{-3}$ & 320,86 \\
$\mathrm{~N}$ & $\mathrm{~g} \mathrm{dm}^{-3}$ & 18,2 \\
$\mathrm{P}$ & $\mathrm{g} \mathrm{dm}^{-3}$ & 7,6 \\
$\mathrm{~K}$ & $\mathrm{~g} \mathrm{dm}^{-3}$ & 3,8 \\
$\mathrm{Ca}$ & $\mathrm{g} \mathrm{dm}^{-3}$ & 208,4 \\
$\mathrm{Mg}$ & $\mathrm{g} \mathrm{dm}^{-3}$ & 21,3 \\
$\mathrm{~S}$ & $\mathrm{~g} \mathrm{dm}^{-3}$ & 4,6 \\
$\mathrm{Fe}$ & $\mathrm{g} \mathrm{dm}^{-3}$ & 1,4 \\
$\mathrm{Zn}$ & $\mathrm{g} \mathrm{dm}^{-3}$ & 0,076 \\
$\mathrm{Cu}$ & $\mathrm{g} \mathrm{dm}^{-3}$ & 0,0095 \\
$\mathrm{Mn}$ & $\mathrm{g} \mathrm{dm}^{-3}$ & 0,0718 \\
$\mathrm{~B}$ & $\mathrm{~g} \mathrm{dm}^{-3}$ & 0,059 \\
$\mathrm{Na}$ & $\mathrm{g} \mathrm{dm}^{-3}$ & 20,8 \\
$\mathrm{Cr}$ & $\mathrm{g} \mathrm{dm}^{-3}$ & 17,5
\end{tabular}

$\mathrm{pH}=$ Potencial hidrogeniônico; $\mathrm{C} / \mathrm{N}=$ relação entre carbono/nitrogênio; MOT = massa orgânica total; MOC = massa orgânica compostável; $\mathrm{C}$ org. = carbono orgânico; $\mathrm{N}=$ nitrogênio; $\mathrm{P}=$ fósforo; $\mathrm{K}=$ potássio; $\mathrm{Ca}=$ cálcio; $\mathrm{Mg}=$ magnésio; $\mathrm{S}=$ enxofre; $\mathrm{Fe}=$ ferro; $\mathrm{Zn}=$ zinco; $\mathrm{Cu}=$ Cobre; $\mathrm{Mn}=$ manganês; $\mathrm{B}=$ boro; $\mathrm{Na}=$ sódio e $\mathrm{Cr}=$ cromo.

Quatro sementes por tubete de volume de $50 \mathrm{~mL}$ foram semeadas da cultivar de mamão Sunrise Solo BS 2000. Os tubetes foram previamente preenchidos com os substratos em teste, com auxílio de uma mesa agitadora, sendo posicionados em bandejas. Durante os sete primeiros dias após a semeadura foram contabilizados o número de plântulas emergidas, apresentando os resultados em percentagem de emergência (EMER); velocidade de emergência (VE) $\left(\mathrm{dia}^{-1}\right)$; índice de velocidade de emergência (IVE), calculado pela equação proposta por Maguire (1962) e; tempo médio de emergência (TME) (dias), obtido por meio de contagens diárias das sementes emergidas após a semeadura, sendo calculado através de fórmula proposta por Labouriau (1983).

Aos 35 dias após a semeadura foram realizadas análises finais, sendo a época considerada pelos produtores de mamão a se realizar o transplantio, a fim de evitar o estiolamento (SERRANO et al., 2010). As seguintes características foram avaliadas: altura da plântula (AP) $(\mathrm{cm})$, diâmetro da copa (DCOP) (mm) e diâmetro do caule (DC) (mm), com auxílio de paquímetro, área foliar $(\mathrm{AF})\left(\mathrm{cm}^{2}\right)$, medida com aparelho medidor de área foliar modelo LI-3100 AREA METER e contagem do número de folhas (NF).

Avaliações gravimétricas de massa fresca da parte aérea (MFPA) $\left(\mathrm{g} \mathrm{pl}^{-1}\right)$ e massa fresca da raiz (MFR) $\left(\mathrm{g} \mathrm{pl}^{-1}\right)$ foram realizadas. Após, esses materiais foram levados para secagem em estufa de circulação de ar forçada à $72^{\circ} \mathrm{C}$ durante 72 horas e, posteriormente, pesados em balança analítica de precisão, obtendo-se a massa seca da parte aérea (MSPA) $\left(\mathrm{g} \mathrm{pl}^{-1}\right)$ e massa seca da raiz (MSR) ( $\left.\mathrm{g} \mathrm{pl}^{-1}\right)$, totalizando a massa seca total da plântula (MST) $\left(\mathrm{g} \mathrm{pl}^{-1}\right)$.

Com base nesses resultados, foi calculado o Índice de Qualidade de Dickson (IQD) (DICKSON et al., 1960), por meio da fórmula:

$$
\mathrm{IQD}=\left[\frac{\mathrm{MST}(\mathrm{g})}{\left(\frac{\mathrm{AP}(\mathrm{cm})}{\mathrm{DC}(\mathrm{mm})}\right)+\left(\frac{\operatorname{MSPA}(\mathrm{g})}{\operatorname{MSR}(\mathrm{g})}\right)}\right]
$$

Os dados obtidos foram submetidos à análise de variância pelo teste $\mathrm{F}$ e, havendo significância, foram confeccionados gráficos de regressões lineares elaborados. As médias dos tratamentos também foram comparadas pelo teste de Dunnett a 5\% de probabilidade, utilizando o tratamento com 
100\% de Carolina II® como testemunha. As análises estatísticas foram realizadas no programa computacional ASSISTAT versão 7.7pt (SILVA; AZEVEDO, 2016).

\section{RESULTADOS E DISCUSSÃO}

As características de percentagem de emergência, tempo médio de emergência, velocidade de emergência e número de folhas das mudas de mamão tiveram como resultados que as adições em até $30 \%$ de lodo de curtume não promoveram prejuízos se comparadas ao uso de apenas substrato comercial (T-00). A proporção de $30 \%$ de lodo obteve resultado similar ao tratamento sem adição do resíduo (T-00), para o índice de velocidade emergência (Tabela 3).

A altura da muda foi afetada negativamente pela incorporação do resíduo ao substrato comercial, visto que os valores médios foram inferiores em todas as formulações contendo o lodo de curtume quando comparadas ao T-00. Os tratamentos contendo até $15 \%$ de lodo de curtume não influenciaram o desenvolvimento do caule e a expansão da área foliar, em relação ao tratamento sem adição de resíduo (T-00) (Tabela 3).

Almeida et al. (2017) comentam que o desejável é obter maiores índices de emergência, já que resultam em menores gastos com aquisição de substratos. Pesquisa de Gondin et al. (2015) com mudas de paricá retrata que o substrato para propagação de plantas pode variar, afetando a germinação das sementes. Todavia, o teor de massa orgânica presente em resíduos de origem animal, como o lodo de curtume, favorece a germinação, resultando em plântulas de maior vigor (GONÇALVES et al., 2016). Por isso, pressupõem-se que no caso de emergência de plântulas de mamão, as proporções acima de $30 \%$ lodo de curtume podem desencadear distúrbios a essa frutícola, visto que esse resíduo curtumeiro foi benéfico para emergência de outras espécies, como maracujá-amarelo (SILVA et al., 2019) e pimenta doce (BERILLI et al., 2019), quando associado a diferentes fontes de substrato.

Os baixos índices de emergência podem estar relacionados a elementos no lodo de curtume que podem provar perturbações as sementes, devido à alta presença do sódio (BERILLI et al., 2014; 2015). Bonatti et al. (2017) obtiveram percentagem de emergência de mudas de mamão Sunrise Solo acima de 90\%, com substratos à base resíduos orgânicos. De acordo com pesquisa de Dassie et al. (2017), o número de folhas e altura de plantas são parâmetros utilizados como referência para indicar o momento ideal de transplantio de mudas a campo.

Para mudas de mamão, em geral, são consideradas aptas ao transplantio aquelas com aproximadamente $10 \mathrm{~cm}$ de altura (SERRANO et al., 2010). Dessa forma, apenas o tratamento T-00 alcançou valores próximos da altura padrão. Todavia, Morais et al. (2017) obtiveram

Tabela 3. Médias dos valores de percentagem de emergência (EMER); tempo médio de emergência (TME); velocidade de emergência (VE); índice de velocidade de emergência (IVE); número de folhas (NF); altura da planta (AP); diâmetro caule (DC) e; área foliar (AF) de mudas de mamão cultivar Sunrise Solo BS 2000

\begin{tabular}{ccccccccc}
\hline Tratamento & $\begin{array}{c}\text { EMER } \\
(\%)\end{array}$ & $\begin{array}{c}\text { TME } \\
\text { (dias) }\end{array}$ & $\begin{array}{c}\text { VE } \\
\left(\mathrm{dia}^{-1}\right)\end{array}$ & IVE & $\begin{array}{c}\text { NF } \\
(\text { und })\end{array}$ & $\begin{array}{c}\text { AP } \\
(\mathrm{cm})\end{array}$ & $\begin{array}{c}\text { DC } \\
(\mathrm{mm})\end{array}$ & $\begin{array}{c}\text { AF } \\
\left(\mathrm{cm}^{2}\right)\end{array}$ \\
\hline T-00 & 61,00 & 15,60 & 0,06 & 0,81 & 6,00 & 8,10 & 2,67 & 19,00 \\
T-15 & 38,80 & 15,16 & 0,07 & $0,45^{*}$ & 6,20 & $5,68^{*}$ & 2,62 & 16,53 \\
T-30 & 47,00 & 16,13 & 0,06 & 0,61 & 5,30 & $4,92^{*}$ & $2,19^{*}$ & $6,57^{*}$ \\
T-45 & $36,00^{*}$ & $19,89^{*}$ & $0,05^{*}$ & $0,39 *$ & $4,70^{*}$ & $3,14^{*}$ & $1,74^{*}$ & $2,06^{*}$ \\
T-60 & $35,00^{*}$ & $19,25^{*}$ & $0,05^{*}$ & $0,39 *$ & $4,70^{*}$ & $3,51^{*}$ & $1,71^{*}$ & $1,51^{*}$ \\
\hline Média & 43,56 & 17,21 & 0,06 & 0,53 & 5,38 & 5,07 & 2,18 & 9,13 \\
\hline CV (\%) & 30,10 & 11,49 & 10,89 & 32,78 & 7,81 & 14,63 & 9,81 & 25,86 \\
\hline
\end{tabular}

Médias seguidas por * na coluna são estatisticamente diferentes do tratamento com substrato comercial (T-00) ao nível de 5\% de probabilidade pelo teste de Dunnett. 
mudas de mamão com padrão comercial quando submetidas a substratos convencional e comercial.

Valores semelhantes aos aqui obtidos para diâmetro do caule foram encontrados em trabalho de Oliveira et al. (2019), utilizando substratos a base de resíduo de café e substrato comercial. Porém, Morais et al. (2017), obtiveram valores de diâmetro do caule de mudas de mamão cv. Sunrise Solo acima dos encontrados na presente pesquisa, com substratos comercial e convencional, à base de solo, areia e esterco bovino.

$\mathrm{O}$ rendimento de massa das mudas de mamão apresentou interferência negativa em função das adições do lodo de curtume a mistura com substrato comercial, uma vez que os valores médios desses parâmetros (MFR, MSR, MFPA e MSPA) foram inferiores aqueles proporcionados pelo tratamento com 100\% de substrato comercial (Tabela 4). Inicialmente, pressupõem-se que adições de até $15 \%$ de lodo podem substituir uma parte do substrato comercial, sem prejuízos a qualidade das mudas de mamão, indicando ser um meio de reduzir o consumo desse tipo de substrato.
Matias et al. (2019), utilizando substrato à base de solo e esterco bovino. A composição do substrato influencia na qualidade de mudas de mamão, sendo observado diferenças significativas em trabalhos de Costa et al. (2017), Rosa et al. (2018) e Matias et al. (2019). Por isso, o lodo de curtume quando misturado a outros resíduos orgânicos proporcionou boa qualidade de mudas (SALES et al., 2018; QUARTEZANI et al., 2018; BERILLI et al., 2018).

Sugere-se, portanto, que existam no lodo de curtume elementos que interfiram negativamente nos processos de emergência e no desenvolvimento e qualidade das mudas de mamão. Espera-se que com maiores proporções desse resíduo, sejam ofertadas maiores quantidades de nutrientes as mudas de mamão, em teores superiores ou semelhantes aos já disponibilizados pelo substrato comercial, pois o lodo de curtume foi referenciado em pesquisas de Berilli et al. (2019), Almeida et al. (2017) e Quartezani et al. (2018), contendo teores consideráveis de massa orgânica, nitrogênio, potássio, cálcio e magnésio, essenciais ao crescimento das plantas.

Por outro lado, algumas espécies de plantas possuem uma maior sensibilidade ao excesso de sódio e a elementos tóxicos

Tabela 4. Médias dos valores de massa fresca da raiz (MFR); massa seca da raiz (MSR); massa fresca da parte aérea (MFPA); massa seca da parte aérea (MFPA) e; índice de qualidade de Dickson (IQD) de mudas de mamão cultivar Sunrise Solo BS 2000

\begin{tabular}{|c|c|c|c|c|c|}
\hline Tratamento & MFR & MSR & MFPA & MSPA & IQD \\
\hline $\mathrm{T}-00$ & 1,3235 & 0,1074 & 0,7499 & 0,1231 & 0,0555 \\
\hline $\mathrm{T}-15$ & 0,7191* & $0,0642 *$ & $0,6218 *$ & $0,0958 *$ & 0,0440 \\
\hline $\mathrm{T}-30$ & $0,3418 *$ & $0,0271^{*}$ & 0,3339* & $0,0486 *$ & 0,0185* \\
\hline $\mathrm{T}-45$ & $0,0950 *$ & $0,0074 *$ & $0,1441^{*}$ & $0,0175^{*}$ & $0,0059 *$ \\
\hline T-60 & $0,0924^{*}$ & $0,0200 *$ & $0,1577^{*}$ & $0,0203^{*}$ & $0,0127 *$ \\
\hline Média & 0,5144 & 0,0452 & 0,4015 & 0,0610 & 0,0273 \\
\hline CV (\%) & 35,47 & 41,02 & 18,70 & 23,45 & 27,89 \\
\hline
\end{tabular}

Médias seguidas por * na coluna são estatisticamente diferentes do tratamento com substrato comercial (T00) ao nível de 5\% de probabilidade pelo teste de Dunnett.

Os valores de massa seca da parte aérea e raiz foram próximos ao trabalho de que as outras (PES; ARENHARDT, 2015), indicando que mudas de mamão cv. 
Sunrise Solo podem possuir maior sensibilidade a tais substâncias, tendo em vista que o lodo de curtume, em razão da presença do sódio em excesso e cromo, possivelmente afetou o desenvolvimento de mudas de café conilon (BERILLI et al., 2014) e palmeira-garrafa (BERILLI et al., 2018).

Sobretudo, o aumento proporcional de $\mathrm{pH}$ pode ter afetado negativamente $\mathrm{o}$ crescimento das mudas, principalmente quanto a produção de massa das raízes. Níveis elevados de $\mathrm{pH}$ podem limitar a absorção de nutrientes, sendo que danos causados pelo aumento de $\mathrm{pH}$ em substrato foram percebidos na produção de mudas de mamão (PAIXÃO et al., 2012).

Em relação as análises de regressão, houve diferenças significativas $(\mathrm{p}<0,01)$ para as proporções de lodo de curtume em mistura ao substrato comercial. De uma maneira geral, quanto maiores as porções de lodo de curtume, menores foram as médias dos parâmetros estudados. Para as variáveis de percentagem de emergência, velocidade de emergência e índice de velocidade de emergência, nota-se um padrão de resposta similar, de forma que as linhas de tendência declinaram com as maiores proporções de lodo de curtume (Figura 1).
Enquanto que, para o tempo médio de emergência, a curva de tendência seguiu uma resposta ascendente, o que significa que quanto maior a porção de lodo de curtume no substrato, maior é o tempo para as plântulas de mamão emergirem (Figura 1). Diante disso, o lodo de curtume pode conter elementos que interferem negativamente nos processos germinativos, em especial, o sódio (BERILLI et al., 2014; 2015). As elevadas concentrações de sais estimulam a redução do potencial hídrico do substrato, que induzem a uma menor capacidade de absorção de água pelas sementes, em função dos efeitos osmóticos e tóxicos (SECCO et al., 2010).

Possivelmente, as sementes de mamão foram submetidas a algum tipo de estresse salino, comprometendo a emergência das mesmas. Isso colabora com a pesquisa de Cavalcante et al. (2010), que identificaram que altos níveis de salinidade causam danos a emergência de sementes da cultivar Sunrise Solo e ainda com experimento de Alves et al. (2015), onde observaram que a velocidade de germinação de plântulas de Sunrise Solo foi prejudicada pelo excesso de sais.

Para as características de desenvolvimento vegetativo das mudas de mamão, percebe-se que o lodo de curtume

Figura 1. Efeito dos tratamentos sobre as variáveis de percentagem de emergência, tempo médio, velocidade de emergência e índice de emergência de mudas de mamão cv. Sunrise Solo BS 2000. ** $1 \%$ de probabilidade.
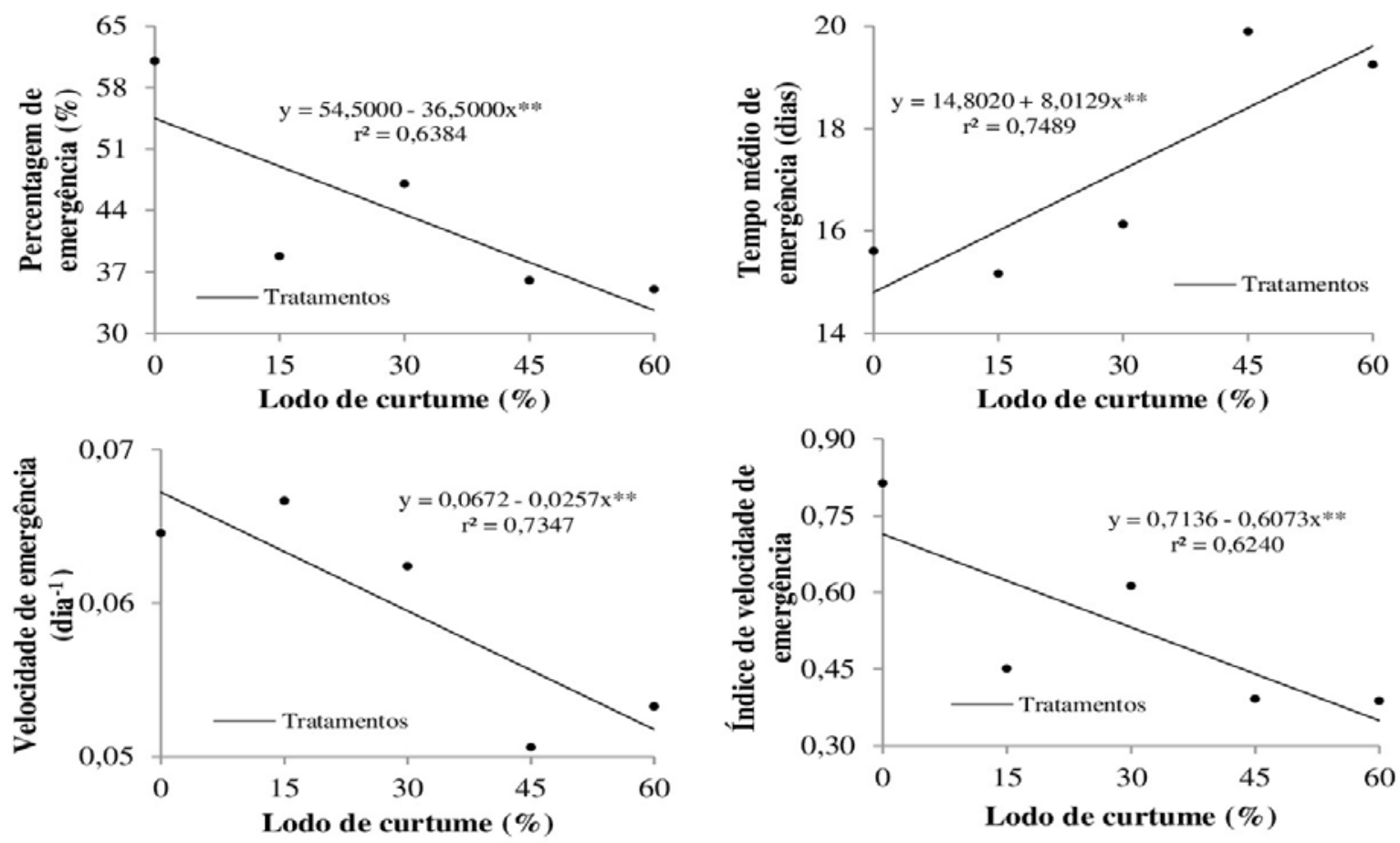
limitou o desenvolvimento dessas, visto que os aumentos graduais desse resíduo causaram decréscimo em suas médias (Figura 2). É válido destacar que a composição química e orgânica do substrato afeta o estado nutricional e o desenvolvimento das mudas, também após a germinação (DIAS et al., 2008), já que as variáveis de desenvolvimento vegetativo tiveram desempenho semelhante aos parâmetros de emergência.
A absorção e ação do íon $\mathrm{Na}^{+}$ inserido nos substratos propostos por meio do resíduo curtumeiro pode ser capaz de inibir as atividades enzimáticas, contribuindo para redução do desenvolvimento das mudas. Este íon ainda pode prejudicar os processos fotossintéticos, reduzindo a área foliar e o número de folhas (FREITAS et al., 2013). Além do mais, os efeitos negativos da salinidade já foram percebidos no número

Figura 2. Efeito dos tratamentos sobre as variáveis biométricas de mudas de mamão. ** $1 \%$ de probabilidade.
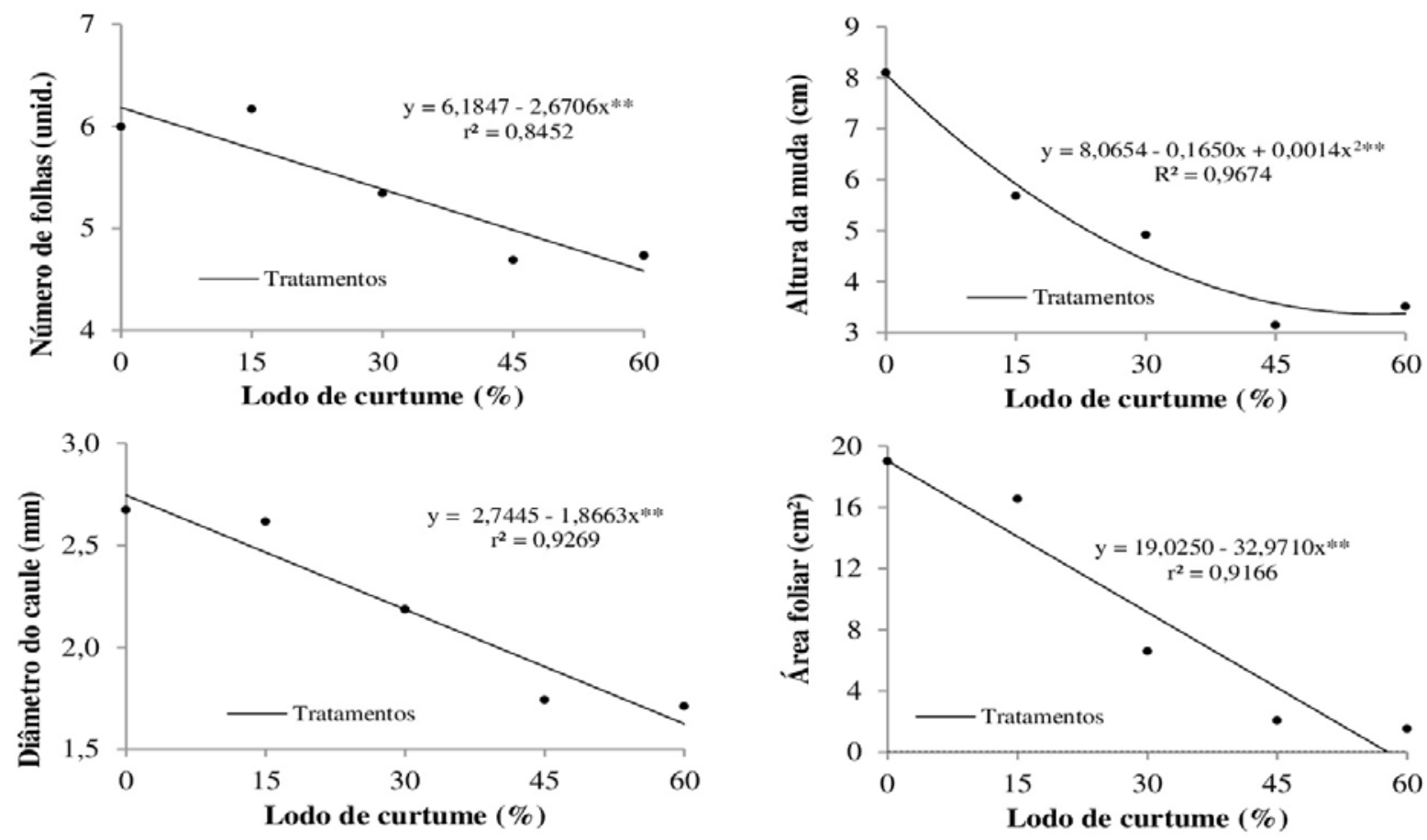

O número de folhas seguiu resposta semelhante as demais variáveis expostas aos tratamentos com lodo de curtume. As folhas estão diretamente relacionadas ao desenvolvimento da muda, pois é o principal órgão da planta onde ocorre a fotossíntese (COSTA JÚNOIR et al., 2017). Ademais, um número maior de folhas relaciona-se a uma maior área ativa fotossintética, demonstrando mudas de maior resistência as adversidades do campo (NASCIMENTO et al., 2019). Em vista disso, a área foliar das mudas de mamão também foi afetada negativamente pelas adições graduais do lodo de curtume, principalmente as plântulas submetidas a maior concentração testada.

de folhas de mudas de mamoeiro (DINIZ et al., 2018), assim como a influência negativa do aumento de $\mathrm{pH}$ no substrato para mudas dessa frutícola (PAIXÃO et al., 2012).

Assim como nos demais parâmetros, o diâmetro do caule também foi comprometido pelo lodo de curtume, sendo que o excesso de $\mathrm{Na}^{+}$possivelmente prejudicou seu desenvolvimento. Plantas de mamão irrigadas com soluções contendo teores consideráveis de sais, tiveram o diâmetro do caule reduzido pelo acréscimo de sódio (MESQUITA et al., 2014; DINIZ et al., 2018). Para mais, os valores dessa característica podem variar, já que substratos à base de resíduo de 
tanque de piscicultura afetaram significativamente o diâmetro do caule de mudas de mamão (ROSA et al., 2018).

Em relação as variáveis gravimétricas, os efeitos do lodo de curtume influenciaram no acúmulo de biomassa das mudas (Figura 3).
Nota-se que, a qualidade das mudas de mamão foi influenciada negativamente pela adição do lodo de curtume ao substrato comercial, sendo que quanto maior a porção adicionada, menor a qualidade da muda.

O excesso de sais nos substratos

Figura 3. Efeito dos tratamentos sobre as variáveis gravimétricas de mudas de mamão. ** $1 \%$ de probabilidade.
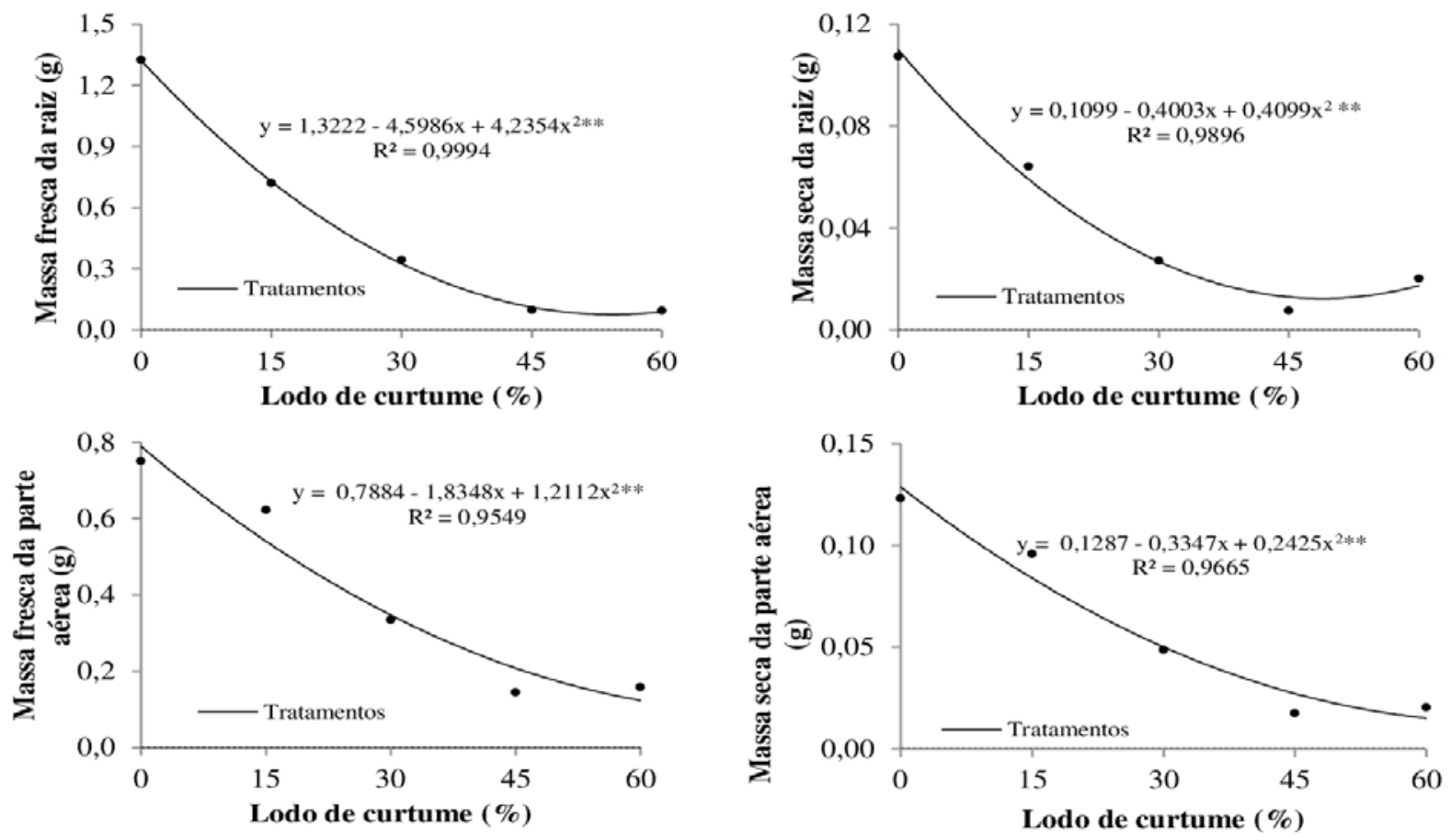

A redução das médias das variáveis de massa fresca e seca das mudas podem estar relacionados a atividade do sódio no substrato. Devido ao estresse salino, a planta modifica suas estruturas morfofisiológicas, acumulando água em seus tecidos (GHEYI et al., 2010), ao invés de crescerem e produzirem biomassa. Isso ainda em função do desequilíbrio nutricional e fisiológico pela alta concentração de sais, influenciando diretamente na conversão de carbono assimilado pelas plantas (TAIZ et al., 2017). Os efeitos danosos do excesso de sais em mamoeiros foram observados em experimentos de Mesquita et al. (2012), Sá et al. (2013) e Diniz et al. (2018).

$\mathrm{Na}$ figura 4 verifica-se as análises de regressão para o índice de qualidade de Dickson de mudas de mamão Sunrise Solo.

Figura 4. Efeito dos tratamentos sobre o índice de qualidade de Dickson de mudas de mamão. ${ }^{* *} 1 \%$ de probabilidade.

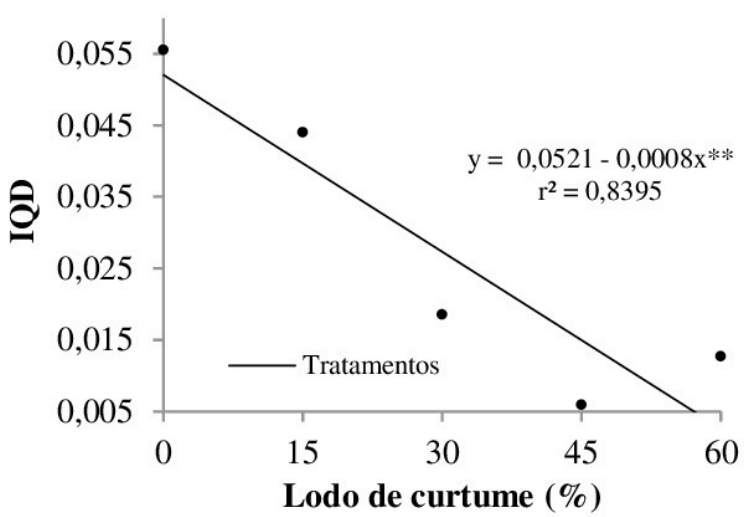

possivelmente promoveu efeitos deletérios as mudas de mamão, culminando em baixos valores de IQD, diferentes dos apresentados em pesquisas de Almeida et al. (2018) e Oliveira et al. (2019). 
Os aumentos nos teores de sódio também prejudicaram as características biométricas e gravimétricas de mudas de mamão Sunrise Solo, consequentemente a sua qualidade (CAVALCANTE et al., 2010). Mesmo que as quantidades de fósforo fornecidas pela combinação do lodo de curtume com substrato comercial sejam consideráveis, estas talvez não possam atenuar os efeitos do estresse salino, reduzindo a qualidade das mudas (DINIZ et al., 2018). O fósforo é um dos elementos relevantes a fotossíntese (DIAS et al., 2009). Este ainda favorece a síntese de amido e sacarose, resultando no maior acúmulo de biomassa e crescimento da planta (TAIZ et al., 2017).

Cabe mencionar que o IQD é considerado um bom indicativo de qualidade de mudas, pois para seu cálculo, envolve-se parâmetros morfológicos importantes como o equilíbrio da distribuição de fitomassa (FREIRE et al., 2015). Este índice tem sido empregado como método de avaliação de qualidade em diversas culturas, além da florestal, como pimenta biquinho (ALMEIDA et al., 2017) e maracujá (SILVA et al., 2019). Vale destacar que, quanto maior o valor de IQD, melhor a qualidade de muda, refletida pela composição do substrato.

\section{CONCLUSÕES}

Os aumentos graduais do lodo de curtume a mistura com substrato comercial de Carolina $\quad \mathrm{II}{ }^{\circledR}$, limitaram proporcionalmente o desenvolvimento e qualidade das mudas de mamão cv. Sunrise Solo BS 2000, nas condições experimentais adotadas.

\section{AGRADECIMENTOS}

Ao Instituto Federal do Espírito Santo (IFES). Ao Conselho Nacional de Desenvolvimento Científico e Tecnológico (CNPq). À Fundação de Amparo à Pesquisa e Inovação do Espírito Santo (FAPES).

\section{REFERÊNCIAS}

ALMEIDA, R. N.; FERRAZ, D. R.; SILVA, A. S.; CUNHA, E. G.; VIEIRA, J. C.; SOUZA, T. S.; BERILLI, S. S. Utilização de lodo de curtume em complementação ao substrato comercial na produção de mudas de pimenta biquinho.

Revista Scientia Agraria, Curitiba-PR, v. 18, n. 1, p. 20-33, 2017.

ALMEIDA, W. A.; UCHÔA, T. L.; SOUZA, L. G. S.; SILVA, N. M.; ARAÚJO NETO, S. E. Aumento da qualidade de mudas de mamoeiro com substrato à base de resíduos. Revista Pesquisa Aplicada e Agrotecnologia, Guarapuava-PR, v. 11, n. 3, p. 113-119, 2018.

ALVES, D. I.; NOIA, L. R.; LOPES, J. C.; MENGARDA, L. H. G. Qualidade

fisiológica de sementes de mamão submetidas a estresse osmótico.

Enciclopédia Biosfera, Jandaia-GO, v. 11, n. 21, p. 1624-1635, 2015.

BARROS, F. L. S.; ARANTES, S. D.; KULCAMP, K. T.; MOREIRA, S. O.; TRINDADE, R. S. Atributos químicos dos frutos de mamoeiros do grupo Formosa cultivados na região norte do Espírito Santo. In: CONGRESSO BRASILEIRO DE FRUTICULTURA, 23., 2014, Cuiabá. Atributos-quimicos [...]. Cuiabá: SBF, 2014. p. 1-5.

BERILLI, S. S.; QUIUQUI, J. P. C.; REMBINSKI, J.; SALLA, P. H. H.; BERILLI, A. P. C. G.; LOUZADA, J. M. Utilização de lodo de curtume como substrato alternativo para produção de mudas de café conilon. Revista Coffee Science, Lavras-MG, v. 9, n. 4, p. 472-479, 2014.

BERILLI, S. S.; BERILLI, A. P. C. G.; CARVALHO, A. J. C.; FREITAS, S. J.; CUNHA, M.; FONTES, P. S. F. Níveis de cromo em mudas de café conilon 
desenvolvidas em substrato com lodo de curtume como adubação alternativa.

Revista Coffee Science, Lavras-MG, v. 10, n. 3, p. 320-328, 2015.

BERILLI, S. S.; SALES, R. A.; BERILLI, A. P. C. G.; PINHEIRO, A. P. B.; PEREIRA, C. P.; GOTTARDO, L. E. Componentes fisiológicos e crescimento inicial de mudas de palmeira-garrafa em resposta a substratos com lodo de curtume. Revista Scientia Agraria, Curitiba-PR, v. 19, n. 1, p. 94-101, 2018.

BERILLI, S. S.; VALADARES, F. V.; SALES, R. A.; ULISSES, A. F.; PEREIRA, R. M.; DUTRA, G. J. A.; SILVA, M. W.; BERILLI, A. P. C. G.; SALLES, R. A.; ALMEIDA, R. N. Use of tannery sludge and urban compost as a substrate for sweet pepper seedlings.

Journal of Experimental Agriculture International, Hooghly, West Bengal, India, v. 34, n. 4, p. 1-9, 2019.

BONATTI, V. F. B.; MOREIRA, E. R.; SOUZA, P. T. Substratos orgânicos na produção de mudas de mamão 'Sunrise Solo’. Revista Tecnologia e Ciência Agropecuária, João Pessoa-PB v. 11, n. 3, p. 31-35, 2017.

CALDEIRA, M. V. W.; PERONI, L.; GOMES, D. R.; DELARMELINA, W. M.; TRAZZI, P. A. Diferentes proporções de biossólido na composição de substratos para a produção de mudas de timbó (Ateleia glazioveana Baill). Scientia Forestalis, Piracicaba-SP, v. 40, n. 93, p. 15-22, 2012.

CAVALCANTE, L. F.; CORDEIRO, J. C.; NASCIMENTO, J. A. M.;

CAVALCANTE, I. H. L.; DIAS, T. J. Fontes e níveis da salinidade da água na formação de mudas de mamoeiro cv. Sunrise Solo. Revista Semina: Ciências Agrárias, Londrina-PR, v. 31, n. 1, p. 1281-1290, 2010.
COSTA, F. C. L.; SILVEIRA, A. T. L.; NOGUEIRA, F. H. M.; SOTERO, A. R. H.; DEUS, M. V. C.; UCHÔA, C. N. Desempenho inicial de mamoeiro em diversos substratos. Revista Internacional de Ciências, Rio de Janeiro-RJ, v. 6, n. 2, p. 191-198, 2016.

COSTA JÚNIOR, E. S.; MATIAS, S. S. R.; MORAIS, D. B.; SOUZA, S. J. C.; SANTOS, G. B.; NASCIMENTO, A. H. Produção de mudas de Carica papaya, tipo formosa, com resíduos de pau de buriti (Mauritia flexuosa L.f.). Revista Brasileira de Ciências Agrárias (Agrária), Recife-PE, v. 40, n. 4, p. 746755, 2017.

COMÉRIO, M.; BERILLI, S. S.; LIMA, C. F.; PINHO, L. G. R.; PEREIRA, L. C.; PINHEIRO A. P. B.; BERILLI, A. P. C. G.; OLIVEIRA, E. C.; ARAUJO, F. O. Efeito da adubação foliar com lodo de curtume na brotação de secções de caule de abacaxizeiro para produção de mudas. Revista Ifes Ciência, Vitória-ES, v. 5, n. 1, p. 170-179, 2019.

DANTAS, J. L. L.; LUCENA, R. S.; VILAS BOAS, S. A. Avaliação agronômica de linhagens e híbridos de mamoeiro. Revista Brasileira de Fruticultura, v. 37, n. 1, p. 138-148. 2015.

DASSIE, L. A.; ALEMAN, C. C.; MOREIRA, A. C. M.; MIGNACCA, F. A.; ZANFOLIN, P. R. L.; CARVALHO, P. R. Produção irrigada de mudas de pimenta dedo de moça (Capsicum baccatum).

Colloquium Agrariae, Presidente Prudente-SP, v. 13, n. 3, p. 128-131, 2017.

DIAS, M. A.; LOPES, J. C.; CORRÊA, N. B.; CUNHA, D.; DIAS, D. C. F. S.

Germinação de sementes e desenvolvimento de plantas de pimenta malagueta em função do substrato e da lâmina de água. Revista Brasileira de Sementes, Londrina-PR, v. 30, n. 3, p. 115-121, 2008. 
DIAS, T. J.; PEREIRA, W. E.;

CAVACANTE, L. F.; RAPOSO, R. W. C.; FREIRE, J. L. O. Desenvolvimento e qualidade nutricional de mudas de mangabeiras cultivadas em substratos contendo fibra de coco e adubação fosfatada. Revista Brasileira de Fruticultura, Jaboticabal-SP, v. 31, n. 2, p. 512-52, 2009.

DICKSON, A.; LEAF, A. L.; HOSNER, J. F. Quality appraisal of white spruce and white pine seedling stock in nurseries. Forestry Chronicle, Mattawa, ON $\mathrm{POH}$ 1V0, Canadá, v. 36, n. 1, p. 10-13, 1960.

DINIZ, G. L.; SALES, G. N.; SOUZA, V. F. O.; ANDRADE, F. H. A.; SILVA, S. S.; NOBRE, R. G. Produção de mudas de mamoeiro sob salinidade da água irrigação e adubação fosfatada. Revista Brasileira de Ciências Agrárias (Agrária), RecifePE, v. 41, n. 1, p. 218-228, 2018.

EMPRESA BRASILEIRA DE PESQUISA AGROPECUÁRIA. Produção Brasileira de Mamão em 2017, Embrapa Mandioca e Fruticultura, 2018.

FOOD AND AGRICULTURE ORGANIZATION OF THE UNITED NATIONS. FAOSTAT: Crops 2019. Rome: FAO, 2021. Disponível em: < http://www.fao.org/faostat/en/\#data/QC >. Acesso em: 12 abri. 2021.

FREITAS, V. S.; MARQUES, E. C.; BEZERRA, M. A.; PRISCO, J. T.; GOMES FILHO, E. Crescimento e acúmulo de íons em plantas de cajueiro anão precoce em diferentes tempos de exposição à salinidade. Revista Semina: Ciências Agrárias, Londrina - PR, v. 34, n. 6, p. 3341-3352, 2013.

FREIRE, A. L. O.; RAMOS, F. R.; GOMES, A. D. V.; SANTOS, A. S.; ARRIEL, E. F. Crescimento de mudas de Craibeira (Tabebuia aurea (Manso) Benth.
\& Hook) em diferentes substratos. Revista Agropecuária Científica no Semiárido, Campina Grande-PB, v. 11, n. 3, p. 38-45, 2015.

GHEYI, H. R.; DIAS, N. S.; LACERDA, C. F. Manejo da salinidade na agricultura: Estudo básico e aplicados. Fortaleza: INCT Sal, 2010.

GONÇALVES, F. C. M.; ARRUDA, F. P.; SOUZA, F. L.; ARAÚJO, J. R.

Germinação e desenvolvimento de mudas de pimentão Cubanelle em diferentes substratos. Revista Mirante, AnápolisGO, v. 9, n. 1, p. 35-45, 2016.

GONDIN, J. C.; SILVA, J. B.; ALVES, C. Z.; DUTRA, A. S.; JUNIOR, L. E.; Emergência de plântulas de Schizolobium amazonicum Huber ex Ducke (CAESALPINACEAE) em diferentes substratos e sombreamento. Revista

Ciência Agronômica, Fortaleza-CE, v. 46, n. 2, p. 329-338, 2015.

\section{LABOURIAU, L. G. A germinação das} sementes. Lima: Secretaria Geral da OEA, 1983. (Serie de Biologia, 24).

MAGUIRE, J. D. Speed of germination aid in selection and evaluation for seedling emergence and vigour. Crop Science, Washington, Estados Unidos, v. 2, n. 2, p. 176-177, 1962.

MATIAS, S. S. R.; COSTA JUNIOR, E. S.; MORAIS, D. B.; SILVA, R. L.; SOUZA, S. J. C. Substratos orgânicos na produção de mudas do mamoeiro havaí. Revista Magistra, Cruz das Almas-BA, v. 30, p. 179-188, 2019.

MESQUITA, F. O.; RODRIGUES, R. M.; MEDEIROS, R. F.; CAVALCANTE, L. F.; BATISTA, R. O. Crescimento inicial de Carica papaya sob irrigação com águas salinas em solo com biofertilizante bovino. Revista Semina: Ciências Agrárias, 
Londrina-PR, v. 33, n. 1, p. 2689-2704, 2012.

MESQUITA, F. O.; CAVALCANTE, L. F.; BATISTA, R. O.; MEDEIROS, R. F.; RODRIGUES, R. M.; SANTOS, W. O. Avaliação da taxa de crescimento absoluto de mamão Havaí sob o efeito salino e de biofertilizante: Parte I. Revista Magistra, Cruz das Almas-BA, v. 26, n. 4, p. 443455, 2014.

MORAIS, T. L.; COSTA, A. C.; MENEZES, M.; SOUZA, M. E. Produção de mudas de mamoeiro em função de diferentes substratos. Revista Cultivando o Saber, Cascavel-PR, v. 10, n. 4, p. 408420, 2017.

NASCIMENTO, K. S.; CUNHA JUNIOR, J. A. N.; SOUZA FILHO, J. F.; SILVA, M. A. Substratos a base de esterco de animais para produção de mudas de mamoeiro. Revista PesquisAgro, Confresa-MT, v. 2, n. 1, p. 57-66, 2019.

NOMURA, M.; PEREIRA FILHO, J. M.; COSTA, E. M.; PEREIRA, L. S.; VENTURA, M. V. A. Avaliação de diferentes quantidades de hidrogel na produção de mudas de mamão Papaya.

Revista Ipê Agronomic Journal, Goianésia-GO, v. 3, n. 1, p. 19-25, 2019.

OLIVEIRA, V. S.; CARVALHO NETO, A. C.; SOUZA, F. H.; BOHRY, L.; SOUZA, J. C.; PLOTEGHER, R. T.; PINHEIRO, A. P. B.; BERILLI, S. S.; BERILLI, A. P. C. G.; SCHMILDT, E. R. Utilização de palha de café como substrato alternativo para produção de mudas de mamoeiro. Revista Ifes Ciência, VitóriaES, v. 5, n. 1, p. 180-188, 2019.

PAIXÃO, M. V. S.; SCHMILDT, E. R.; MATTIELLO, H. N.; FERREGUETTI, G. A.; ALEXANDRE, R. S. Frações orgânicas e mineral na Produção de mudas de mamoeiro. Revista Brasileira de
Fruticultura, v. 34, n. 4, p. 1105-1112, 2012.

PES, L. Z.; ARENHARDT, M. H. Fisiologia Vegetal. Santa Maria, Rio Grande do Sul: Universidade Federal de Santa Maria, Rede E-Tec Brasil, 2015. 81p.

PLUGARU, S.; ORBAN, M.; SARB, A.; RUSU, T. Chromium: toxicity and tolerance in plants. A review. Journal of Environmental Research and Protection, Cluj-Napoca-Romênia, v. 13, n. 4, p. 13-18, 2016.

POSSATO, E. L.; SCARAMUZZA, W. L. M. P.; WEBER, O. L. S.; NASCENTES, R.; BRESSIANI, A. L.; CALEGARIO, N. Atributos químicos de um cambissolo e crescimento de mudas de eucalipto após adição de lodo de curtume contendo cromo. Revista Árvore, Viçosa-MG, v. 38, n. 5, p. 847-856, 2014.

QUADRO, M. S.; ANDREAZZA, R.; TEDESCO, M. J.; GIANELO, C.; BARCELOS, A. A.; BORTOLON, L. Teores de cromo ligados aos óxidos de ferro em áreas de descarte de lodo de curtume. Revista Engenharia Sanitária Ambiental, Rio de Janeiro-RJ, v. 23, n. 1, p. 63-67, 2018.

QUARTEZANI, W. Z.; SALES, R. A.; PLETSCH, T. A.; BERILLI, S. S.; NASCIMENTO, A. L.; HELL, L. R.; MANTOANELLI, E.; BERILLI, A. P. C. G.; SILVA, R. T. P.; TOSO, R. Conilon plant growth response to sources of organic matter. African Journal of Agricultural Research, Victoria Island, Lagos, Nigeria, v. 13, n. 4, p. 181-188, 2018.

ROSA, D. K. O. F.; BARROS, D. L.; AIRES, F. P. G.; GOMIDE, P. H. O. Aproveitamento do resíduo de tanque de piscicultura na produção de mudas de mamoeiro em Rorainópolis. Revista 
Ambiente: Gestão e Desenvolvimento, Boa Vista-RR, v. 11, n. 1, p. 120-136, 2018.

SÁ, V. S.; BRITO, M. E. B.; MELO, A. S.; ANTÔNIO NETO, P.; FERNANDES, P. D.; FERREIRA, I. B. Produção de mudas de mamoeiro irrigadas com água salina.

Revista Brasileira de Engenharia Agrícola e Ambiental, Campina GrandePB, v. 17, n. 10, p. 1047-1054, 2013.

SALES, R. A.; SALES R. A.; SANTOS, R. A.; QUARTEZANI, W. Z.; BERILLI, S. S.; OLIVEIRA, E. C. Influência de diferentes fontes de massa orgânica em componentes fisiológicos de folhas da espécie Schinus Terebinthifolius Raddi. (Anacardiaceae). Revista Scientia Agraria, Curitiba-PR, v. 19, n. 1, p. 132141, 2018.

SECCO, L. B.; QUEIROZ, S. O.; DANTAS, B. F.; SOUZA, Y. A.; SILVA, P. P. Germinação de sementes de melão (Cucumis melo L.) em condições de estresse salino. Revista Verde de Agroecologia e Desenvolvimento Sustentável, Mossoró-RN, v. 4, n. 4, p. 129-135, 2010.

SERRANO, L. A. L.; CATTANEO, L. F.; FERREGUETTI, G. A. Adubo de liberação lenta na produção de mudas de mamoeiro. Revista Brasileira de Fruticultura, Jaboticabal-SP, v. 32, n. 3, p. 874-883, 2010.

SILVA, F. A. S.; AZEVEDO, C. A. V. The Assistat Software Version 7.7 and its use in the analysis of experimental data.

African Journal of Agricultural

Research, Victoria Island, Lagos, Nigeria, v. 11, n. 39, p. 3733-3740, 2016.

SILVA, L. G. F.; SALES, R. A.; ROSSINI, F. P.; VITÓRIA, Y. T.;

BERILLI, S. S. Emergência e desenvolvimento de plântulas de maracujáamarelo em diferentes substratos. Revista
Energia na Agricultura, Botucatu/SP, v. 34, n. 1, p. 18-27, 2019.

SILVA-MATOS, R. R. S.; SILVA JUNIOR, G. B.; MARQUES, A. S.; MONTEIRO, M. L.; CAVALCANTE, I. H. L.; OSAJIMA, J. A. New organic substrates and boron fertilizing for production of yellow passion fruit seedlings. Archives of Agronomy and Soil Science, Berlin, v. 62, n. 3, p. 445455, 2016.

SOUSA, V. F. O.; SANTOS, G. L. Elemento Cromo na Nutrição Mineral de Plantas. Revista da Universidade Vale do Rio Verde, Três Corações-MG, v. 16, n. 2, p. 1-7, 2018.

TAIZ, L.; ZEIGER, E.; MOLLER, I.; MURPHY, A. Fisiologia e desenvolvimento vegetal. 6 . ed. Porto Alegre: Artmed, 2017. 